\title{
Functional compensation in partially denervated muscles
}

\author{
A. J. McCOMAS', R. E. P. SICA, M. J. CAMPBELL ${ }^{2}$, AND A. R. M. UPTON \\ From the Regional Neurological Centre, Newcastle General Hospital, \\ Newcastle upon Tyne
}

SUMMARY In patients with various types of chronic motor denervation, the numbers of surviving motor units have been compared with the twitch tensions developed by the same muscle (extensor digitorum brevis). It was found that functional compensation in partially denervated muscles was often marked; in most patients abnormally small twitches occurred only when fewer than $10 \%$ of motor axons remained. The factors responsible for this compensation are considered. The twitch speeds of partially denervated muscles differed markedly, even among patients with the same disorder; there was evidence to suggest that the twitches of some motor units might become slower than those found in normal muscles.

When a muscle loses part of its nerve supply two types of compensatory adjustment can occur provided that sufficient time elapses. Firstly, those muscle fibres which have retained their innervation may hypertrophy. Secondly, collateral reinnervation may take place - that is, new nerve sprouts may grow out from surviving nerve axons to supply denervated muscle fibres. Even in experimentally denervated animal muscles little is known about the functional effectiveness of these compensatory changes, while in man the requisite type of investigation has not been made previously. In the present study we shall report the results of a quantitative study of motor units in extensor digitorum brevis muscles of patients with a variety of chronic denervating disorders. The study has involved estimating the number of motor units in each muscle and comparing this with the isometric twitch tension. The most important finding has been the very considerable increase in force which could be exerted by surviving motor units; this increase was sufficient to compensate for quite severe amounts of denervation. A preliminary account of some of this work has already been given (McComas and Sica, 1971).

\section{METHODS}

Altogether 36 patients were examined; they were aged 18 to 61 years and, on clinical grounds, were judged to

${ }^{1}$ M.R.C. External Scientific Staff.

${ }^{2}$ Formerly British Council Scholar, now at Hospital Ramos Mejia, Buenos Aires, Argentina. have had denervation of leg muscles for longer than six months. The patients could be divided into three groups (Table). The first and largest group comprised those patients suffering from motor neurone disease. Patients with the Kugelberg-Welander syndrome made up a second group, while the remaining group included patients with miscellaneous disorders-hereditary ataxia, idiopathic and carcinomatous polyneuropathies, prolapsed lumbar intervertebral discs, peroneal muscular atrophy, and old poliomyelitis. The numbers of men and women in each group are given in the Table, together with their mean ages. Fifty healthy subjects aged 18 to 59 years served as controls for one or more investigations. The number of motor units in the extensor digitorum brevis (EDB) muscle was estimated by the method of McComas, Fawcett, Campbell, and Sica (1971a). Isometric twitch parameters were measured in the extensor hallucis brevis muscle (most medial subdivision of the EDB muscle belly) using techniques described by Sica and McComas (1971). In most patients concentric needle electromyography was performed and measurements were made of impulse conduction velocity in motor nerve fibres; these additional studies often served to clarify a diagnosis but the results will not be reported. Unless stated otherwise, mean values have been given with their standard deviations. The significance of the difference between two means was calculated by the $t$ test.

\section{RESULTS}

NUMBERS OF UNITS The mean number of motor units in the EDB muscles of control subjects was $199 \pm 60$ and the smallest estimate was 121 (McComas et al., 1971a). Any patient with fewer than 121 units 
TABLE

DETAILS OF PATIENTS IN THREE GROUPS

\begin{tabular}{|c|c|c|c|c|c|}
\hline Condition & $\begin{array}{l}\text { Total no. } \\
\text { patients }\end{array}$ & Male & Female & $\begin{array}{c}\text { Mean } \\
\text { age }(y r .)\end{array}$ & $\begin{array}{c}\text { Range } \\
\text { (yr.) }\end{array}$ \\
\hline Motor neurone disease & 18 & $\begin{array}{c}11 \\
(13)\end{array}$ & $\begin{array}{c}7 \\
(8)\end{array}$ & $47 \cdot 6$ & $33-61$ \\
\hline $\begin{array}{l}\text { Kugelberg-Welander } \\
\text { Miscellaneous }\end{array}$ & $\begin{array}{r}8 \\
10\end{array}$ & $\begin{array}{l}5 \\
5\end{array}$ & $\begin{array}{l}3 \\
5 \\
(6)\end{array}$ & $\begin{array}{l}35 \cdot 9 \\
41 \cdot 3\end{array}$ & $\begin{array}{l}18-56 \\
19-59\end{array}$ \\
\hline
\end{tabular}

Figures in parentheses denote numbers of legs investigated.

was therefore regarded as exhibiting denervation. In general, the patients with most denervation were those with motor neurone disease; in two of these patients only a solitary unit had survived and the mean number for the whole group was $14 \cdot 3 \pm 17 \cdot 2$. Figure 1(a) shows muscle responses evoked in a 51 year old man with motor neurone disease, in whom only four units remained after symptomatic weakness of one year's duration. In patients such as this, with so few motor units remaining, it was possible to check the estimated number by observing the electrical activity evoked during a maximal voluntary contraction. In four patients with motor neurone disease the EDB muscles were examined in both legs and the results were in reasonably good agreement. Thus, in the three patients exhibiting severe denervation, the paired values were 1 and 3 , 0 and 5, and lastly 2 and 8 units respectively. In the fourth patient there was relatively slight denervation and the estimated numbers of units in the two legs were 61 and 73.

Patients with the Kugelberg-Welander syndrome were less severely affected by denervation; the smallest estimate was 9 units and the mean $63 \pm 38$. Two other adults with this syndrome, both of whom displayed marked wasting of thigh muscles, possessed numbers of units which were within the normal range for EDB. These last results (143 and 165 units respectively) have not been included in this study, nor have those for three children with spinal muscular atrophy. One of these was a 4 year old boy with an estimated 32 units; in two girls aged 8 and 9 there were 47 and 82 units respectively.

The numbers of units remaining in the patients with miscellaneous denervating disorders varied considerably, ranging from 11 to 81 (mean $35 \pm 26$ units). One further patient, with peroneal muscular atrophy, was totally denervated and therefore could not be included in the study. Also excluded were subjects beyond the age of 61 , though we have reported elsewhere that denervation is the most important cause of muscle wasting in the elderly (Campbell and McComas, 1970).

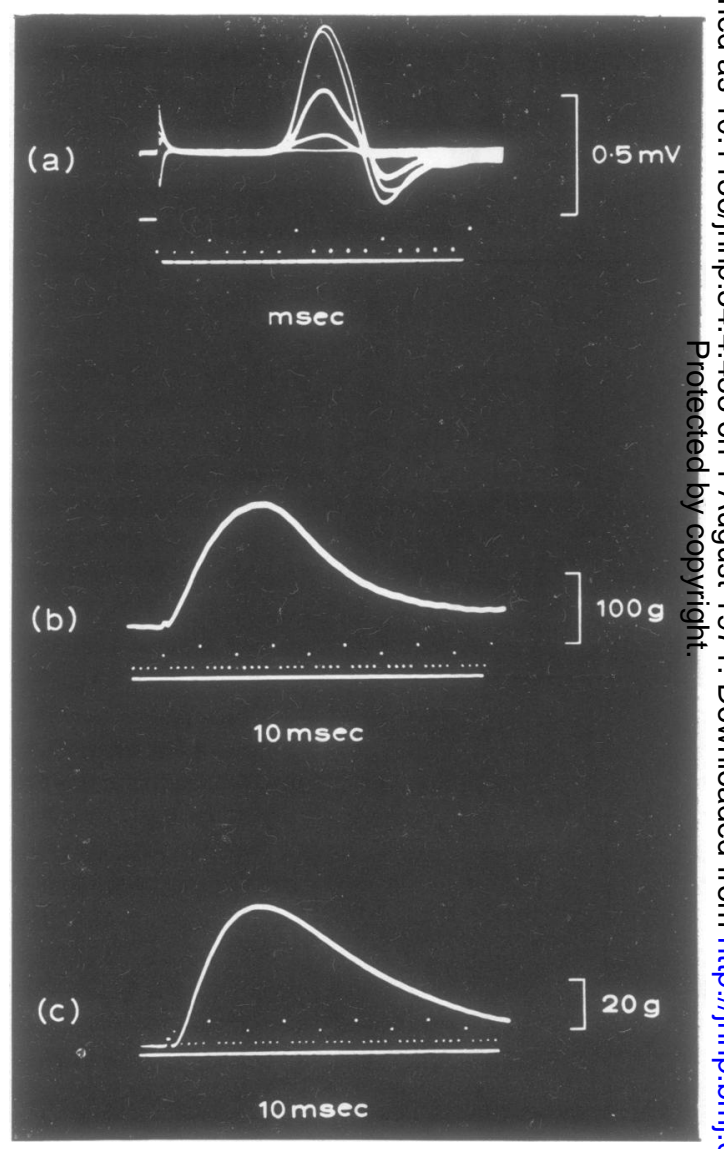

FIG. 1. (a) Evoked responses in EDB muscle of patient with motor neurone disease; only four increments could be 윽 differentiated as the stimulus was raised from a threshold to a supramaximal intensity. (b) Slow isometric twitch in patient with idiopathic polyneuropathy; contraction and half-relaxation times 130 and 100 msec respectively. O (c) Large single unit twitch in patient with severe denerva- $N$ tion (see text). Twitch tension, $60 \mathrm{~g}$; contraction time, 응 $110 \mathrm{msec}$; half-relaxation time, $145 \mathrm{msec}$. 
In some partially denervated muscles, it was occasionally observed that the potential of a newly recruited motor unit might cause a reduction and not an increase in the evoked muscle response. This decrement was presumably caused by temporal or spatial dispersion-that is, by delayed impulse conduction in motor nerve fibres or by the establishment of neuromuscular junctions outside the normal endplate zone of the muscle.

NUMBER OF UNITS
AMPLITUDES OF MOTOR UNIT POTENTIALS In control subjects the mean amplitude of the evoked motor unit potentials was $28 \cdot 9 \pm 27 \cdot 1 \mu \mathrm{V}$ and potentials larger than $100 \mu \mathrm{V}$ were encountered infrequently (Fig. 2). These values may be compared with those of the severely denervated muscle of Fig. 1a where it can be seen that successive motor unit potentials had amplitudes of $80,260,295$, and $90 \mu \mathrm{V}$. Figure 2 shows that these enhanced responses were typical (a)

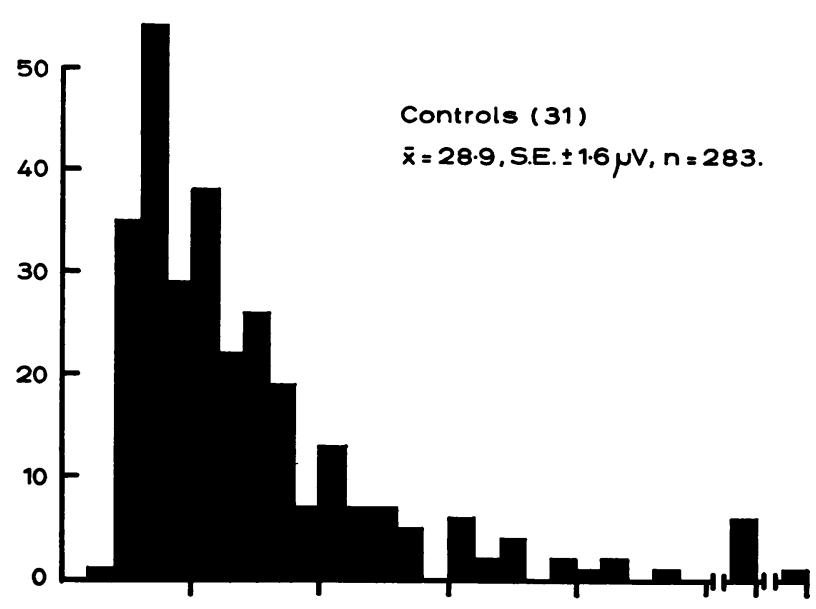

(b)

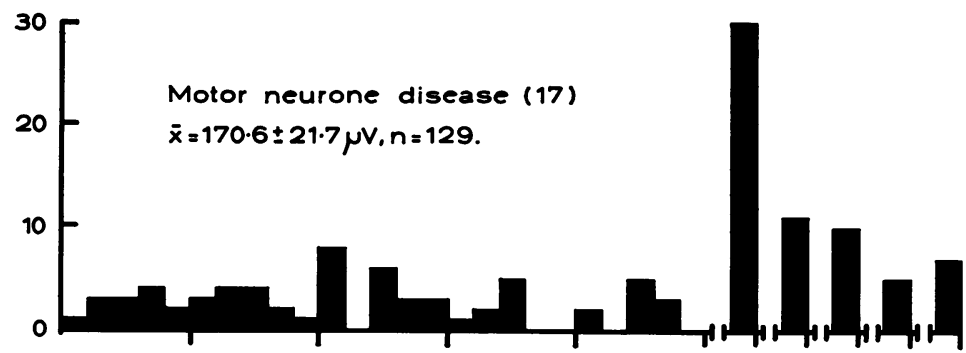

(c)

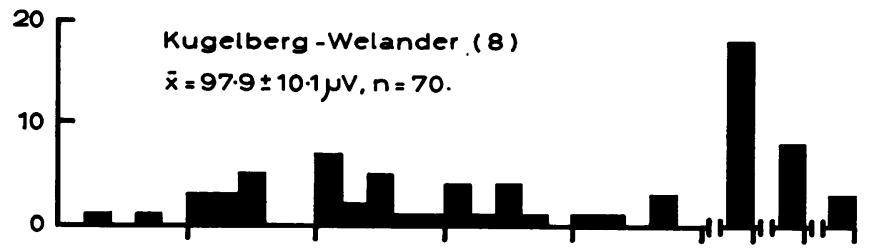

(d)

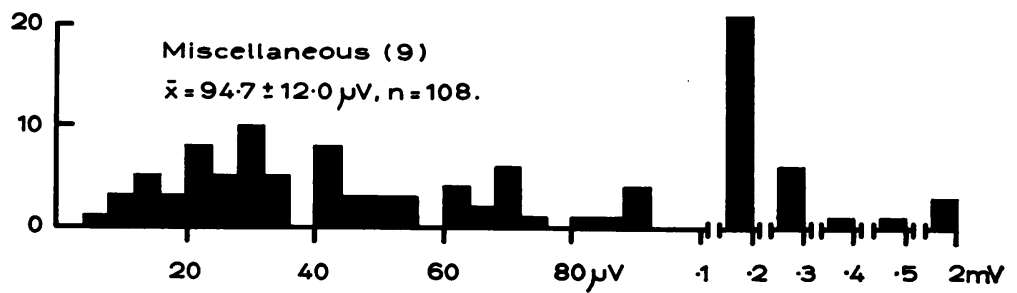

FIG. 2. Amplitudes of motor unit potentials in control subjects and patients. (a) 283 units in 31 controls $(\bar{x}=28 \cdot 9, S E \pm 1 \cdot 6$ $\mu \mathrm{V}$ ). (b) 129 units in 17 patients with motor neurone disease $(\bar{x}=170 \cdot 6, \pm 21 \cdot 7 \mu \mathrm{V})$.

(c) 70 units in eight patients with Kugelberg-Welander syndrome $(\bar{x}=97.9 \pm 10 \cdot 1 \mu \mathrm{V})$. (d) 108 units in nine patients with miscellaneous neuropathies $(\bar{x}=94 \cdot 7 \pm 12 \cdot 0 \mu V)$.

AMPLITUDE OF MOTOR UNIT POTENTIAL 
of partially denervated muscles. In this Figure the motor unit potential amplitudes have been pooled for each of the three groups of patients; subtractive responses (see above) have been included and their polarity ignored. The mean potential amplitudes for each group were significantly larger than that for the controls.

In Fig. 3 the mean sizes of the motor unit potential amplitudes have been plotted as a function of the numbers of surviving units. If the surviving motor units had been unchanged, the potential amplitudes would have fallen along the interrupted line running horizontally. In fact, it can be seen that the mean sizes of the motor unit potentials increased as the number of remaining units declined; in the most extreme case a single surviving unit had a potential amplitude of more than $1 \mathrm{mV}$. Finally, the sloping line in Fig. 3 shows the degree of enhancement which would have been required if the maximum evoked muscle response were to be maintained at the mean control level $(5 \cdot 3 \mathrm{mV})$.

\section{ISOMETRIC TWITCHES}

a. Whole extensor hallucis brevis (EHB) muscles In many patients the isometric twitch tensions remained

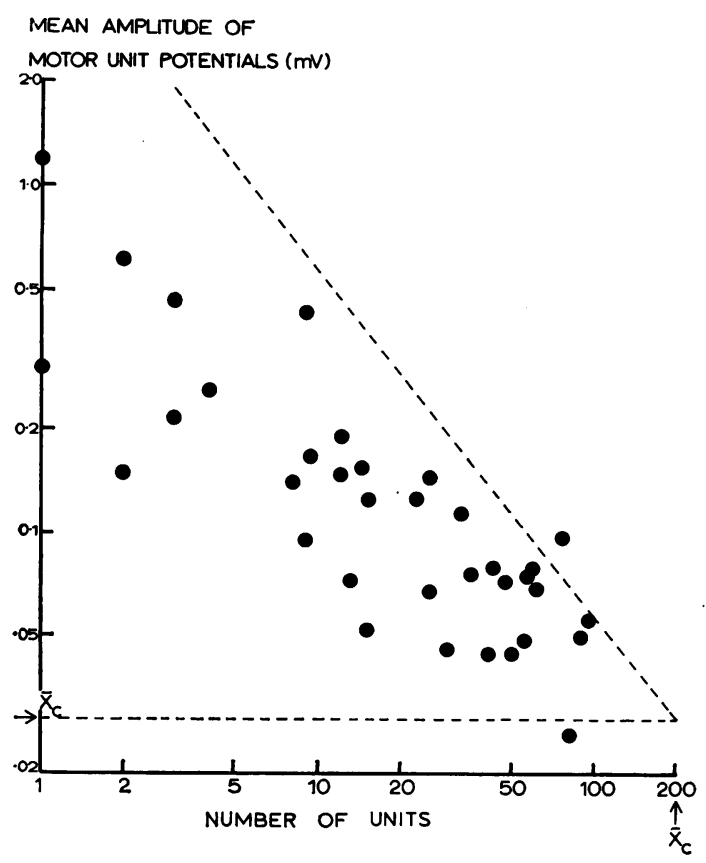

FIG. 3. Mean amplitudes of motor unit potentials in 35 muscles with different amounts of denervation; Note logarithmic axes. within the control range of values despite severe $\overline{\mathbb{D}}$ denervation. This point is evident in Fig. 4 where the tensions have been plotted as a function of the number of surviving motor units. It can be seen that of the 14 muscles retaining more than 20 units, only 0 one developed an abnormally small tension. The time courses of the isometric twitches varied greatly among different patients, even among those with the same disease. In each group of disorders, however, $:$ the mean contraction and half-relaxation times were $\vec{F}$ significantly prolonged (Fig. 5a, b). The slowest twitch in this study was encountered in a 59 year old man with an idiopathic polyneuropathy of $15 \frac{\mathrm{c}}{\mathrm{m}}$ years standing; the contraction time was $130 \mathrm{msec} \underset{\widetilde{\phi}}{\overrightarrow{0}}$ and the half-relaxation time $100 \mathrm{msec}$ (Fig. 1b).

b. Single motor unit twitches In addition to the $\vec{\circ}$ whole muscle twitches described above, the contractile responses of 31 single units in 25 patients $\vec{\omega}$ were also examined (Fig. 6a, b). It was found that, although many of the twitch tensions were within the normal range, there were some which were very much greater. The largest tension recorded was $60 \mathrm{~g}$ (Fig. 1c) and was observed in a 19 year old gif with peroneal muscular atrophy, in whom 14 unit of remained. As with the whole muscle responses, the

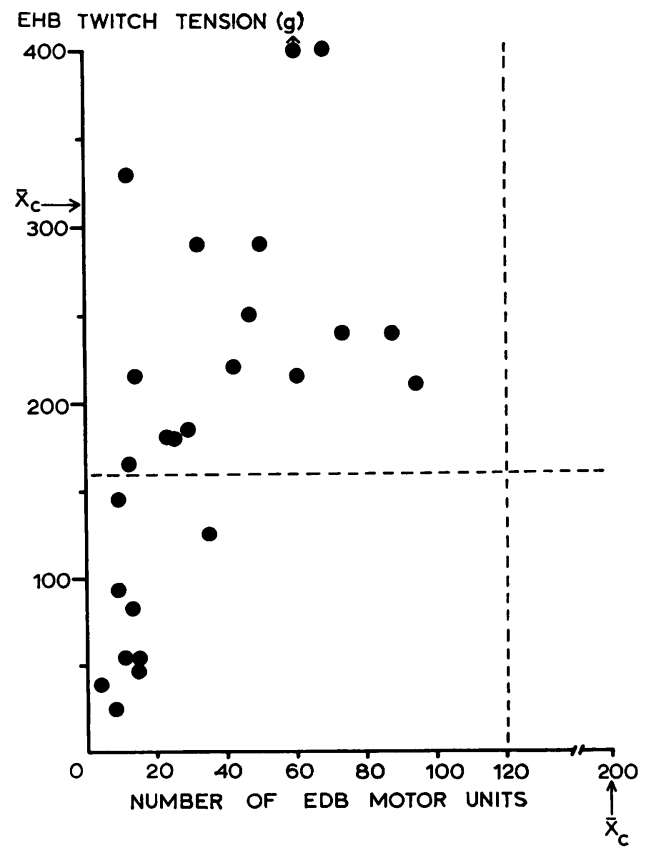

FIG. 4. EHB twitch tensions in 25 muscles with different $\mathrm{N}$ amounts of denervation. Interrupted lines denote lower limits of respective normal ranges; $X_{c}$, mean control value.

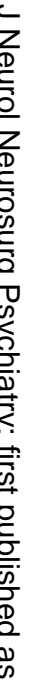



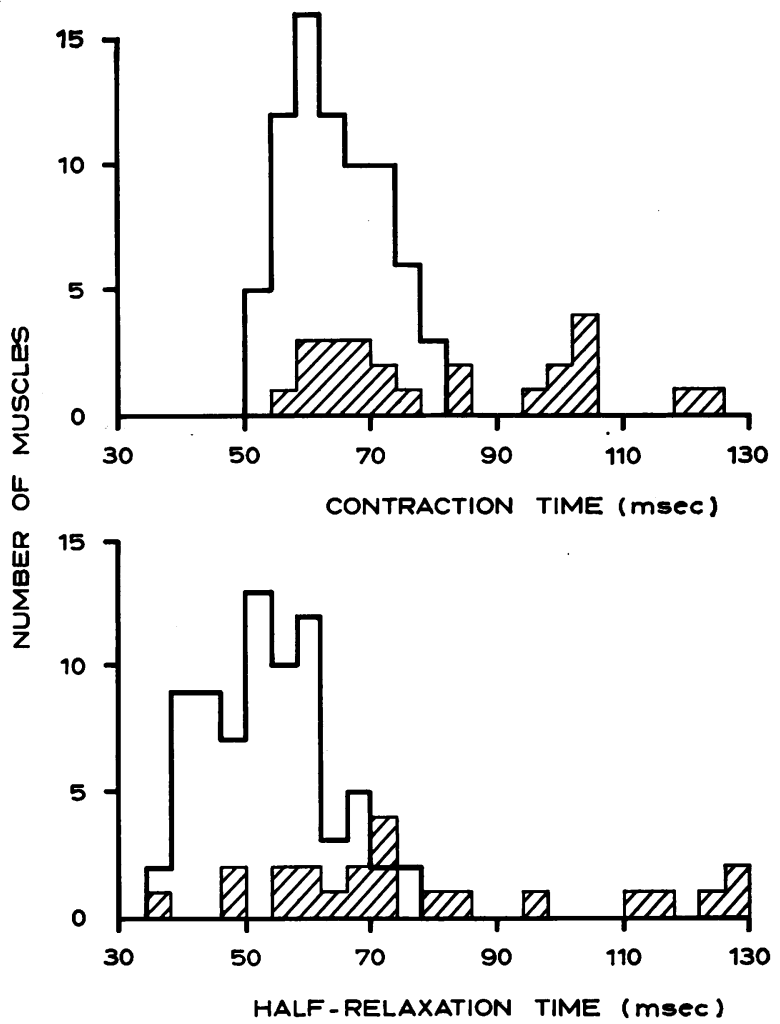

FIG. 5. (a) Contraction times of EHB twitches in 74 control muscles (open columns) and 24 muscles in patients (hatched columns). Mean values in controls and patients were $63.4 \pm 7.2 \mathrm{msec}$ and $81.4 \pm 21.0 \mathrm{msec}$ respectively. (b) Corresponding half-relaxation times; mean values in controls and patients were $52.5 \pm 9.7 \mathrm{msec}$ and $76.9 \pm 26 \cdot 7$ msec respectively.

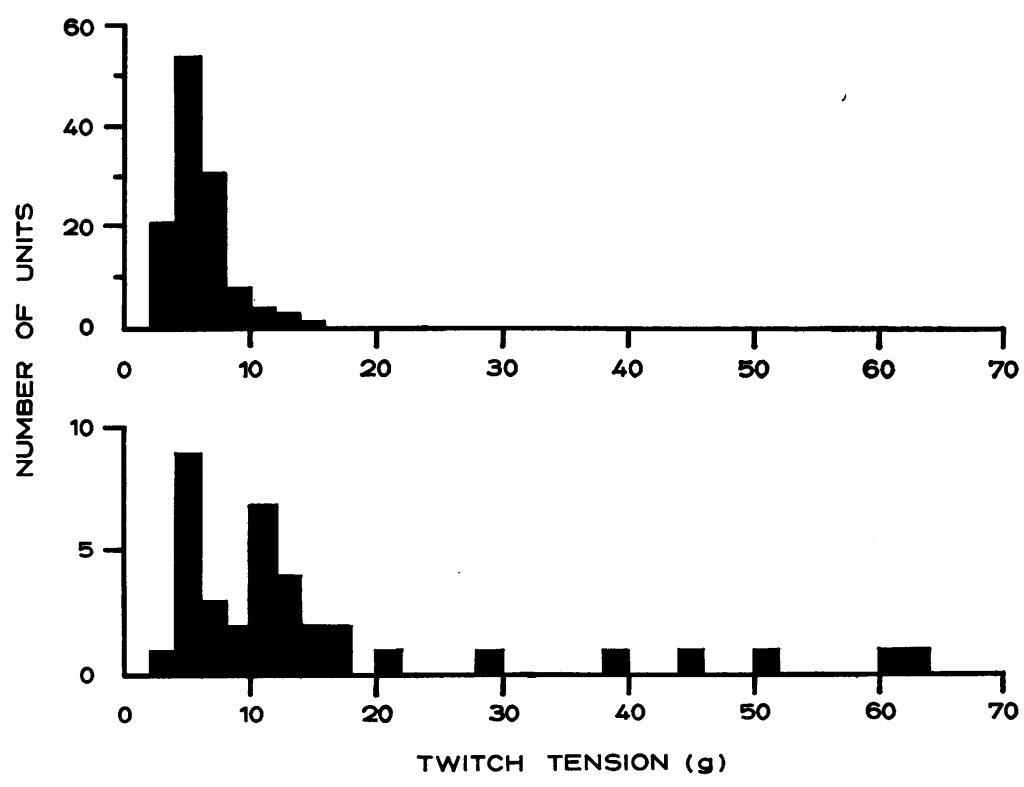

FIG. 6a. Twitch tensions of 122 single motor units in 31 control subjects (upper) and of 37 units in 26 patients (lower); mean tensions were $5 \cdot 5 \pm 2 \cdot 2 \mathrm{~g}$ and $15 \cdot 6 \pm 16 \cdot 2 \mathrm{~g}$ respectively. 


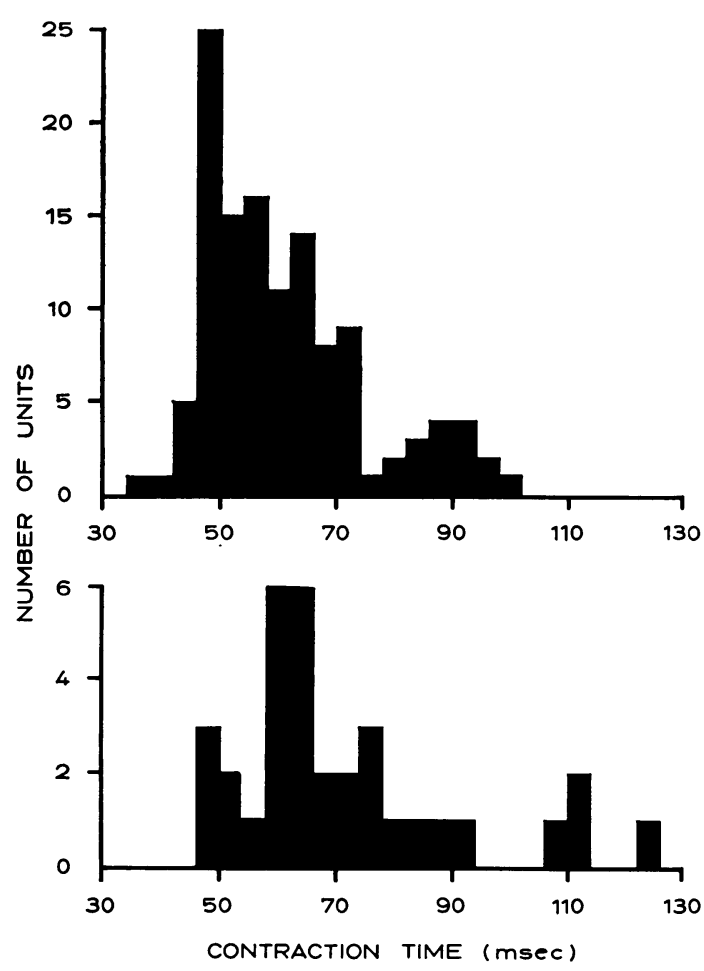

FIG. 6b. Contraction times of single motor unit twitches in controls (upper) and patients (lower).

time courses of the single unit twitches varied considerably, ranging from 46 to $125 \mathrm{msec}$.

\section{DISCUSSION}

The purpose of this study has been to examine the degree of functional compensation which may occur in partially denervated muscles. In an investigation of this kind, it was not possible to determine the twitch tensions of muscles before the onset of illness, and therefore the extent of weakness in a given muscle could not be estimated. Nevertheless, the results have been striking, for they have shown that muscles may still exert twitch tensions within the normal range until fewer than 20 motor units are left. Since the mean number of units estimated in control subjects was $199 \pm 60$, a residuum of 20 units would correspond to $90 \%$ denervation. Such a result clearly indicates that individual motor units surviving in partially denervated muscles can develop greater than normal tensions. This conclusion was borne out by the studies on single motor units, several of which were found to have very large twitches. While the significance of such enhanced responses is evident, the interpretation of the normal sized motoro unit twitches is more difficult because of the design of the experiment. Thus, only the tension developed 0 by the most medial subdivision of the EDB muscle belly was measured. If, during reinnervation, the $\frac{\rho}{\square}$ territory of a single motor unit had extended into more than one subdivision of EDB, the maximum? twitch tension would be underestimated.

Unfortunately, differing conclusions have been $\stackrel{5}{+}$ drawn from the results of previous studies which? have dealt with motor unit territory in partially $\frac{\bar{c}}{\bar{c}}$ denervated muscles. Erminio, Buchthal, and Rosen- $\vec{\nabla}$ falck (1959), on the basis of recordings made in various muscles with a multi-lead electrode, concluded that the territory is increased. In contrast, $\vec{\circ}$ Kugelberg, Edström, and Abbruzzese (1970) observed no evidence of extended territory in a more $\vec{\omega}$ direct study made in the rat tibialis anterior muscle? In the present investigation we have found evidence 3 for increased motor unit territories. Thus, in a nor- $i$ mal EDB muscle each motor unit appears to be + incorporated into only one of the four subdivisions of the muscle belly. In a partially denervated musfe्f it was often possible to see the skin displacemenpso caused by contraction of underlying muscle fibras and the movements of tendons, after excitation o single motor unit. Not infrequently the same uraito appeared to be inserted into two or even three tow instead of only one.

One further explanation of the present resuts must be considered. In their study of patients with.motor neurone disease, Erminio et al. (1959) argued that the apparent increases in motor unit territory were too large to be accounted for by reinnervation alone. These authors postulated that synchronousڤ firing of motoneurones also contributed to the $e_{\Omega}^{\mathbb{Q}}$ enlargement of muscle action potentials. In the $\vec{F}$ present study this interpretation of the enhanced 3 potentials can be excluded since the axons were $\supset$ excited directly. However, Brown and Johns (1970) have recently raised the possibility of ephaptic firing between adjacent units, either nerve or muscle 3 fibres. Although this possibility cannot be excluded? entirely there is some evidence against it. Thus, if an axon were sufficiently damaged for its myelino insulation to break down, then impulse conduction? would be slowed and the evoked muscle action potential would be dispersed temporally as well as spatially. Similarly, if muscle fibres were being stimu $-\frac{7}{O}$ lated by current flowing from adjacent fibres, then a certain amount of time would elapse before excita- $\tilde{N}$ tion had spread out to reach those fibres at the $\mathrm{N}$ fringe of the active zone. Yet our own observations were that individual evoked 'motor unit' potentials 
were neither less regular in configuration nor more dispersed in time than those of control muscles.

Because of the axonal branching described above, the tensions recorded from the great toe alone will sometimes have underestimated the functional capacity of single motor units. In the present study the best estimate of motor unit twitch tension is to compare the ratios of the (EHB) twitch tensions to the numbers of EDB motor units, first in control and then in partially denervated muscles. In control muscles the mean twitch tension was $313 \mathrm{~g}$ and the mean number of EDB units was 199, giving a ratio of $1.6 \mathrm{~g}$ /unit. In the 12 patients with fewer than 15 units, in whom the reinnervation might be expected to be greatest, the corresponding ratio was $11 \cdot 1 \mathrm{~g} / \mathrm{unit}$. In other words, the motor units surviving in severely denervated muscles developed approximately seven times the normal tension.

How is this increase in motor unit twitch tension brought about? At the outset, two possible mechanisms were mentioned-collateral reinnervation and muscle fibre hypertrophy. Since the tension developed by a muscle fibre is proportional to its cross-sectional area, a seven-fold increase in tension could be achieved if the normal number of fibres enlarged their diameters by a factor of $2 \cdot 6$. Although fibre hypertrophy does undoubtedly occur in partially denervated muscles (Adams, Denny-Brown, and Pearson, 1962), it was unlikely to have been the only, and may not even have been the major, factor in the present study. Thus in rat muscles which had been partially denervated by selective diversion of spinal roots Weiss and Edds (1945) found that almost complete functional recovery had occurred without any increase in muscle fibre diameters. This type of study affords powerful, albeit indirect, testimony to the importance of collateral reinnervation. Another approach has been to study the morphology of intramuscular nerve endings after intravital or postmortem staining; in partially denervated muscles profuse sprouting of surviving axons is apparent (for example, Edds, 1950; Coërs and Woolf, 1959). However, the most convincing evidence of collateral reinnervation has come from a recent study in the rat by Kugelberg et al. (1970). These workers stimulated single motor nerve axons repetitively and then used histochemical techniques to reveal the distribution of excited muscle fibres comprising the respective motor units. They found that in partially denervated muscles the mean number of muscle fibres in a motor unit increased by a factor of four. In the present investigation we have obtained convincing though limited evidence for collateral reinnervation by simply inspecting single motor unit twitches on the dorsum of the foot (see above).

How much collateral reinnervation can a single motoneurone undertake? It is not unreasonable to suppose that there must be a limit to the number of sprouts which an axon can grow, and also to the number of muscle fibres which can be adequately supervised by a motoneurone through its trophic controlling mechanism. Yet the present study suggests that the reinnervating capacity of a motoneurone may be surprisingly great. For example, in Fig. 3, there is no suggestion of a plateau in the relationship between the motor unit potential amplitudes and the numbers of surviving units. The largest motor unit potential observed in the present study was about $2 \mathrm{mV}$ and was almost as large as the maximum potentials evoked in the entire EDB muscles of some control subjects. This type of observation prompts another consideration. Is the mechanical efficiency of such a large unit commensurate with its electrical activity - or might the motoneurone control some features of the muscle fibres more completely than others? The simplest answer to this problem has been to calculate the ratio of the maximum twitch tension to that of the maximum evoked muscle response. In controls this ratio was $59 \mathrm{~g} / \mathrm{mV}$, while in muscles with more than $90 \%$ denervation the value was $78 \mathrm{~g} / \mathrm{mV}$. It therefore appears that partially denervated muscles are not inefficient mechanically. The relatively small discrepancy between the results for controls and patients might have been due to experimental error or perhaps to less perfect summation of motor unit potentials in partially denervated muscles (see Results).

The amplitudes of the motor unit potentials are of interest for another reason, since even in a severely denervated muscle units are occasionally encountered which have potential amplitudes within the normal range. We have argued elsewhere (McComas, Sica, and Campbell, 1971b) that these units belong to motoneurones which are dysfunctional; either these neurones have failed to enlarge their unit territory or, having increased it, have been unable to maintain it. It is the presence of these motor units which is thought to be responsible for the so-called 'secondary' myopathic changes in a chronically denervated muscle. Other evidence of motoneurone dysfunction is the decremental nature of the muscle responses after repetitive nerve stimulation; this feature has been previously described in motor neurone disease (Mulder, Lambert, and Eaton, 1959) and was found by us to be equally prominent in the Kugelberg-Welander syndrome and the miscellaneous neuropathies.

Finally, information was obtained in the present investigation about the twitch speeds of partially denervated muscles. It was found impossible to predict the time course of the twitch in a patient with any of the conditions studied, since in each 
disorder the twitch speed could be at either end of the normal spectrum. In addition, there were some patients in whom abnormally slow twitches were recorded. This slowing was not due to reduced muscle temperatures or to repetitive electrical activity in muscle fibres. It was also unlikely that the slowing was due to fibrotic or other 'non-specific' degenerative changes in the muscle, since the twitches of all denervated muscles would have been expected to exhibit similar behaviour. It seems probable that these slow twitches resulted from unusually high proportions of slow twitch units among the surviving populations. However, in some patients the twitches of single units and of whole muscles were slower than those of any motor unit in control subjects. This last observation would suggest that the duration of contractions of individual muscle fibres may be altered beyond the limits imposed within a normal muscle. In this respect it is of interest that slowed contraction has been reported in muscles undergoing excessive stimulation or work hypertrophy (Salmons and Vrbová, 1967; Olson and Swett, 1969). In the absence of single motor unit data, however, it is not possible to determine whether these last results were due to disproportionate hypertrophy of those muscle fibres which already had slow twitches or to actual slowing of contractile responses in individual fibres.

In conclusion, the combination of muscle twitch studies with estimates of numbers of surviving motor units, would appear to offer a valuable means for investigating and quantifying the progressive changes which take place in human muscles deprived of their innervation.

Financial support was received from the Medical Research Council, the British Council the Muscular Dystrophy Group of Great Britain and the Muscular Dystrophy Associations of America, Inc. Our thanks are due to Mr. J. Smith for technical services and to Mrs. Y. Chisholm for secretarial assistance.

\section{REFERENCES}

Adams, R. D., Denny-Brown, D., and Pearson, C. M. (1962). Diseases of Muscle. A Study in Pathology, 2nd ed. Henry Kimpton: London.

Brown, J. C., and Johns, R. J. (1970). Abnormal motor nerve excitability in amyotrophic lateral sclerosis. Johns Hopk. med. J., 127, 55-63.

Campbell, M. J., and McComas A. J. (1970). The effects of ageing on muscle function. Fifth Symposium on Current Research in Muscular Dystrophy and Related Diseases (Abstracts). London.

Coërs, C., and Woolf, A. L. (1959). The Innervation of G5 Muscle. A biopsy study. Blackwell: Oxford.

Edds, M. V., Jr. (1950). Collateral regeneration of residual motor axons in partially denervated muscles. J. exp. Zool., 113, 517-551.

Erminio, F., Buchthal, F., and Rosenfalk, P. (1959). Motor unit territory and muscle fibre concentration in paresis due to peripheral nerve injury and anterior horn cell $\mathscr{\sigma}$ involvement. Neurology (Minneap.), 9, 657-671.

Kugelberg, E., Edström, L., and Abbruzzese, M. (1970). Mapping of motor units in experimentally reinnervated rat muscle. Interpretation of histo-chemical and atrophic fibre patterns in neurogenic lesions. J. Neurol. Neurosurg. Psychiat., 33, 319-329.

McComas, A. J., Fawcett, P. R. W., Campbell, M. J., and Sica, R. E. P. (1971a). Electrophysiological estimation of the number of motor units within a human muscle J. Neurol. Neurosurg. Psychiat., 34, 121-131.

McComas, A. J., and Sica, R. E. P. (1971). Properties motor units in normal and partly denervated huma muscles. J. Physiol (Lond.), 212, 28P-29P.

McComas, A. J., Sica, R. E. P., and Campbell, M. J. (1971b 'Sick' motoneurones. A unifying concept of muscle dis ease. Lancet, 1, 321-325.

Mulder, D. W., Lambert, E. H., and Eaton, L. M. (1959 Myasthenic syndrome in patients with amyotrophic later sclerosis. Neurology (Minneap.), 9, 627-631.

Olson, Camille B., and Swett, C. P. Jr. (1969). Speed contraction of skeletal muscle. The effect of hypoactivity $\overrightarrow{.}$ and hyperactivity. Arch. Neurol. (Chic.), 20, 263-270.

Salmons, S., and Vrbová, G. (1967). Changes in the speed of mammalian fast muscle following long-term stimulation. J. Physiol. (Lond.), 192, 39-40P.

Sica, R. E. P., and McComas, A. J. (1971). Fast and slow twitch units in a human muscle. J. Neurol. Neurosurg. Psychiat., 34, 113-120.

Weiss, P., and Edds, M. V. Jr. (1945). Spontaneous recovery of muscle following partial denervation. Amer.J. Physiol., 145, 587-607. 